\title{
Research and Development Transformation in Central Asia: University-led Research Consortiums
}

\author{
Jayarethanam S. PILLAI ${ }^{*}$, Aureliu SINDILA ${ }^{* *}$, Anna NAGORNOVA ${ }^{* * *}$
}

Received: July 12, 2018

Revised: October 25, $2018 \quad$ Accepted: October 31, 2018.

\begin{abstract}
The growth of knowledge-intensive societies has brought dramatic changes to the higher education landscape, changing the role of universities as well as academiaindustry relationship models. The changing roles of universities in teaching, innovation and entrepreneurial enthusiasm impact the national innovation systems of many developed and developing countries. This paper attempts to study existing models of university-industry collaboration in Central Asia, using structured interviews to provide analytical and practically applicable strategies to address various issues in higher education.
\end{abstract}

Keywords: Knowledge-Intensive, Network, Collaboration, Higher Education, Research Development, Entrepreneurship.

JEL Code Classification: 033; 034; 039; 043; 053

UDC: 334

DOI: https://doi.org/10.17015/ejbe.2018.022.01

\footnotetext{
School of Entrepreneurship and Business Administration, American University of Central Asia, Bishkek, Kyrgyz Republic. E-mail: jayarethanam_s@auca.kg

School of Entrepreneurship and Business Administration, American University of Central Asia, Bishkek, Kyrgyz Republic. E-mail: sindila_a@auca.kg

School of Entrepreneurship and Business Administration, American University of Central Asia, Bishkek, Kyrgyz Republic. E-mail: nagornova_a@auca.kg

Copyright @, 2018 Ala-Too International University.
} 


\section{Introduction}

Lord Dearing, a former Chancellor of The University of Nottingham, said "Just as castles provided the source of strength for medieval towns, and factories provided prosperity in the industrial age, universities are the source of strength in the knowledge based economy of the twenty first century" (MacLeod, 2002). Inspired by Lord Dearing, this paper highlights patterns of how universities undertake research within Central Asia. This research aims to explore the feasibility of university-led collaboration between universities and industry. It analyzes the possibility of sharing university resources, in terms of respective intellectual talent pools, instead of constantly competing for resources, hence, building a solid foundation for R\&D development in Central Asia $(C A)^{1}$. These kinds of collaborative efforts should open more opportunities for inward foreign direct investment (FDI) in areas that have positive implications / spillovers for social and economic development.

It is evident that Science, Technology, Engineering and Mathematics (STEM) research has slowly gained traction in the recent years, it has yet to move forward in a concerted way to catch up with the reset of the develoiping countries in Asia. The stagnation of the former Soviet-bloc countries is partially explained by inability to adopt best practices in its economic and technological transformations (Becker $\&$ Weissenbacher, 2007). One of the crucial mechanisms that this research aims to consider is the role played by university-led research consortiums that attract regional and international investments. In recent years, such practices have been successful in Asia and Europe. Therefore, the question is whether emerging economies of the CIS can implement and manage a network of research consortiums to create a positive spillover effect for R\&D development.

In this paper, we propose to identify contributory effort towards a model of University-led Research Consortium Networks (URCN) that could lead towards several positive spillovers in economic and/or overall regional development. The paper defines a URCN as a group of established universities, which form a network, either between them or with the inclusion of industry, to create mutually beneficial and trustworthy relationships in higher education, research and development. The goal is to open real possibilities for intellectual exchange and mobility in areas of research partnerships, research services and shared infrastructure. The primary goal of such a network is to form a framework along the lines of academic entrepreneurship, which approximates, e.g. the framework of Erasmus+ in the European Union.

Considering the developmental paths of the economies in Central Asia, structural and policy issues continue to deprive these countries of progress along a sustainable economic and technological growth path. There is a slow brain drain

\footnotetext{
${ }^{1}$ Consists of the breakaway Central Asian Republics of the Former Soviet Union - Kazakhstan, Kyrgyzstan, Uzbekistan, Tajikistan and Turkmenistan
} 
from this region, and it only further adds to the economic woes, leaving it with a limited pool of skilled labor. For such progress to come to fruition there is an urgent need to discover new models of technology development. This may be done through collaboration between existing universities and industries, despite the existing financial constraints and dearth of skilled labor. The application of existing models from elsewhere, without an understanding the intricacies of the local growth ecosystem, would only lead to further waste of valuable resources and, ultimately, failure.

What is evident from the existing literature is that universities and industry have been collaborating for decades. However, the emergence of a global knowledge economy has intensified the need for strategic partnerships that go beyond traditional funding of discrete research projects and the tendency of universities, particularly within the region, to develop into silos focused only on academic superiority over their counterparts. While this shows competitive behavior, this type of isolation from industry only makes it harder for local universities to attract investment from outside of academia, or to attract researchers or global research firms to Central Asia. This is exacerbated by the fact that the existing knowledge and skilled labor is sparse, good infrastructure is non-existent and, most importantly, there is very limited understanding of the concept of Public-PrivatePartnership (PPP). Furthermore, economies of scale in R\&D cannot be maximized due to the poor policy and structural conditions of local universities. Before attempting to move forward with these factors, we must briefly highlight the problems.

\subsection{Research Question}

Across CIS economies, the "innovator" role is usually dedicated to each state's respective Academy of Sciences or its scientific analogue. To a certain degree, their role is limited in areas of innovation and there is lack of interaction with industries and firms to generate investment in $R \& D$, as seen by the lack of such activities in general. Sometimes private interest groups, social partners and sub-state governments are involved in formulating the national entrepreneurial strategies. Moreover, they often proactively intervene at an early stage of the policy cycle. In contrast to such elaborate ambitions, the scope of selective systems towards R\&D initiatives is rather modest. The emphasis lies on salient issues and the government is the principal actor in deciding a position. However, it is difficult to state whether governments in these countries are directly involved in fostering R\&D development. Since independence there were various initiatives and policies for small and medium enterprises (SMEs); however, none of them brought the expected results. When analyzing the research and development figures, as a per cent of GDP, Figure 1 shows volatile patterns for both Kazakhstan and Kyrgyzstan between the years of 2000-2010. In order to complete the Central Asian picture, it was necessary to compare the cases of Uzbekistan and Tajikistan, even though indicators are hardly reached an apex of $0.36 \%$ in the case of Uzbekistan in 2000. 
Jayarethanam Sinniah PILLAI, Aureliu SINDILA \& Anna NAGORNOVA

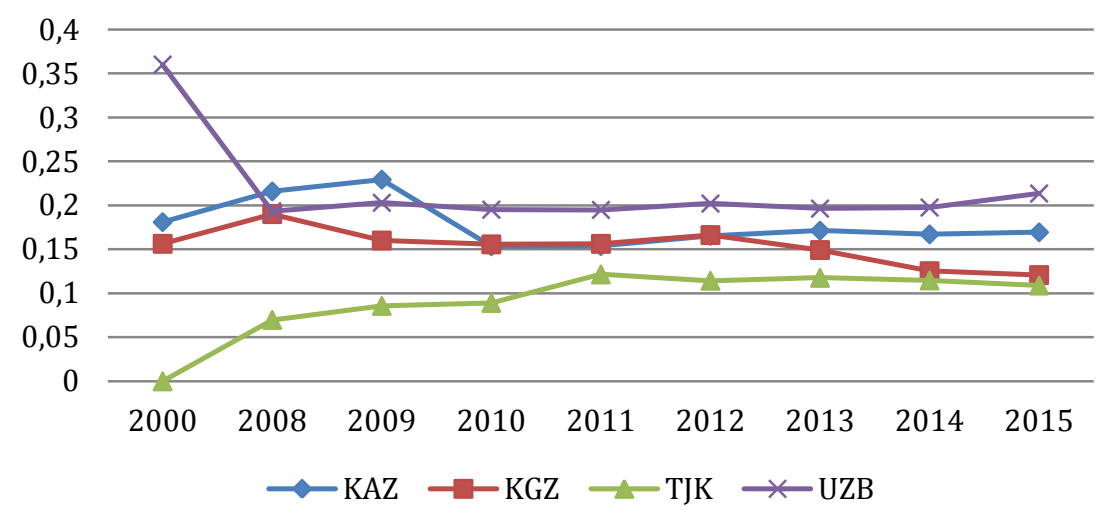

Figure 1. Research and Development Expenditure (\% of GDP)

Source: Compilation from World Bank Data, available online at: https://data.worldbank.org/indicator

This is considerable lower compared to the regional benchmark, which is the member of the Eurasian Economic Union - Russia that spent $1.28 \%$ of GDP in 2003 (Figure 2). Naturally, the inclusion of the Russian Federation into the picture dwarfs the R\&D expenditure of other CA economies.

2,4

2

1,6

1,2

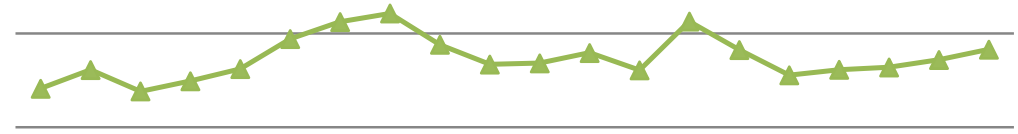

0,8

0,4

0

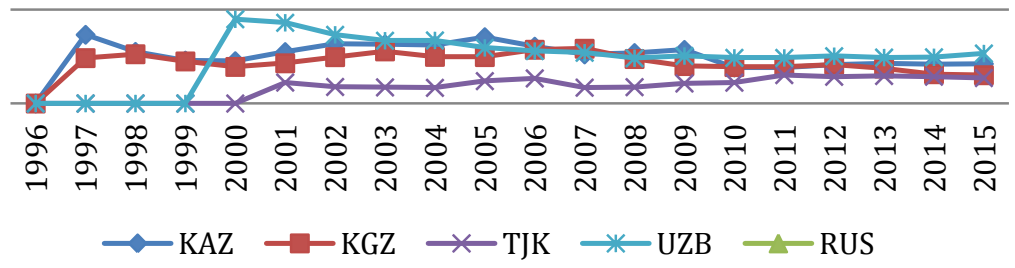

Figure 2. Research and Development Expenditure (\% of GDP), including Russian Federation

Source: Compilation from World Bank Data, available online at: https://data.worldbank.org/indicator 
By contrast, the top performing Asian economies of Japan and the four 'dragons' Taiwan, South Korea, Hong Kong and Singapore - which together constitute less than four percent of the world's population, have progressed along with Europe and North America as one of the three pillars of the modern entrepreneurial world. What is clear from these countries is that there is a strong involvement of the State in developing the right initial conditions along with appropriate and innovative policies to navigate technological advancements. For example, their research and development as a percent of GDP shows a considerably less volatile pattern. With minor exceptions, these cases express a continuously increasing pattern culminating with South Korean indicators of $4.27 \%$ in 2014 (Figure 3).

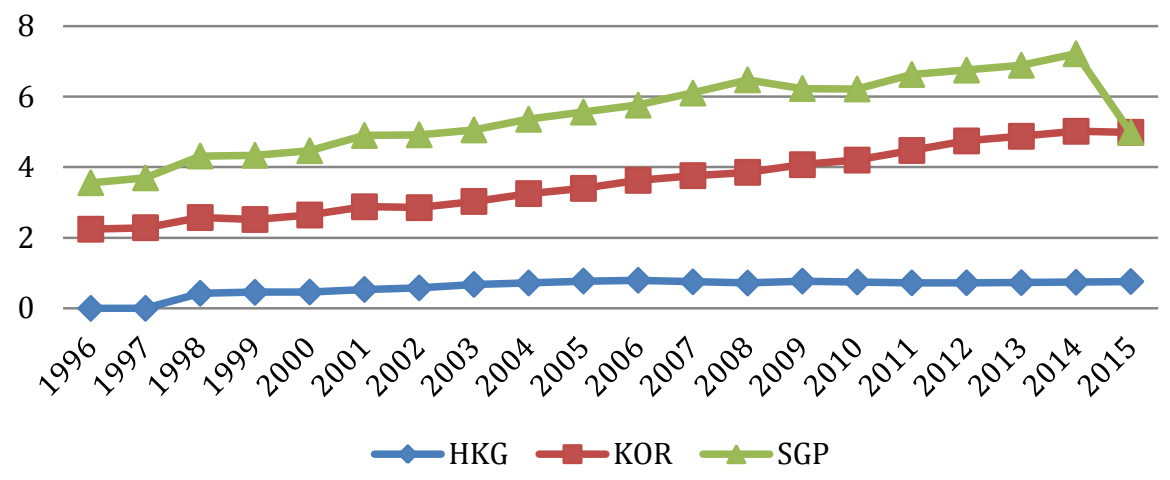

Figure 3. R\&D Expenditure, \% of GDP, S. Korea, Singapore, Hong Kong Source: Compilation from World Bank Data, available online at: https://data.worldbank.org/indicator

Instead of borrowing models developed elsewhere, the "dragons" have adapted lessons from the West to suit their environment, cultural conditions and institutional structures, as opposed to simply importing ideas without due diligence check. While global financial, economic and sovereign debt crises persist, a greater appreciation of the importance of URCNs has become evident among leading academicians and private sector investors. Many affected countries have recently been discussing the question of what measures they can take to strengthen their own entrepreneurial structures and what factors are behind the current successes of the Scandinavian countries and Asian economic giants. Furthermore, there is discussion of how the emerging markets of Central Asia could adopt such practices in a similar or configured form within their respective country situations. This research aims to examine how their objectives could be realized through a regionspecific model, and what obstacles would need to be overcome to achieve these goals. The paper proposes the following hypothetical scenario:

Conjecture: There is an informal variation in the model of the research and development practiced in developed economies, which is similarly utilized among universities in Central Asia, hence the model can be strengthened and built upon for further economic development. 


\section{Methodology}

To derive answers for stated puzzles, formal structured interviews were undertaken in Kyrgyzstan and Kazakhstan. The participating universities were selected randomly. Table 1 shows universities and government agencies involved into structured interviews. Structured intrviews were undertaken in formal setings at their offices. A total of four public institutes, five private universities and one governmental agency were selected. There were a total of fifteen participants interviewed across selected stakeholders who agreed to contribute into research development. The participants held professorship positions in social sciences, research development leading positions and policy making bodies. Interview questions were distributed before formal meeting for interviews. Although the sample size is small, the answers to structured questions revealed similar patterns. Thus, acquired information was crucial for understanding many pertinent issues, which shed a light on potentially larger research and policy study in upcoming months.

Table 1. Research participants

\begin{tabular}{lll}
\hline & \multicolumn{1}{c}{ Public Universities } & \multicolumn{1}{c}{ Private Universities } \\
\hline \multirow{3}{*}{ Kyrgyzstan** } & $\begin{array}{l}\text { Kyrgyz-Russian Slavic University } \\
\text { Kyrgyz Economic University }\end{array}$ & $\begin{array}{l}\text { International Alatoo University } \\
\text { Kyrgyz-Turkish Manas University } \\
\text { American University of Central Asia }\end{array}$ \\
\cline { 2 - 3 } & $\begin{array}{c}\text { *Kyrgyz Patent - State Service of Intellectual Property and Innovation under } \\
\text { the Government of the Kyrgyz Republic }\end{array}$ \\
\hline \multirow{3}{*}{ Kazakhstan } & $\begin{array}{l}\text { Nazarbayev University } \\
\text { Kazakh National Technical Research } \\
\text { University named after K.I.Satpayev }\end{array}$ & $\begin{array}{l}\text { Narxoz University } \\
\text { Almaty Management University }\end{array}$ \\
\hline
\end{tabular}

Note: ${ }^{1}$ The data is collected from official sources.

Additionally, authors collected and manually systematized intellectual property data outputs from national intellectual property offices of Kazakhstan, Kyrgyzstan, Uzbekistan and Tajikistan. We compare sequences of patent data with scientific and technical journal articles in order to build a complete comparison picture that subsequently supports our initial hypothesis. Simultaneously, we designed patent concentration nets for Kazakhstan (Figure 3) and Uzbekistan (Figure 4) that shed a light on research and development activities and their relationship with universities.

In the recent years, numerous attempts have been made to introduce the concept of business incubators in developing economies, including the former Soviet Republics. The five countries which form Central Asia are not evenly served in terms of services provided by their respective governments, business environment, and initiatives from both local and international community. 
In terms of financial support, for instance, the Central Asian countries cannot count on the same access to capital. Those with rich sub-soil easily attract foreign investments and capital to their borders. In comparison, those with few existing natural resources face difficulties in competing and eventually fall short with respect to financial resources. Kazakhstan and Uzbekistan possess deposits of mineral resources; thus, the largest oil companies literally fight to gain access to the vast Kazakh and Uzbek natural resources.

As of 2013, Kazakhstan was the tenth largest exporter and the fifteenth largest producer of crude oil (CIA World Fact Book, 2013). The Kyrgyz Republic occupies the ninety-first rank in terms of oil production and the ninetieth for oil exports. The gap between these two and the poorest countries in the region is enormous.

Consequently, the ability to attract foreign investors is clearly undermined for countries with very restricted access to natural resources. Moreover, wealth is not distributed evenly and the system of redistribution is non-existent. The NGO Transparency International, in its proprietary Corruption perception index 2016, ranked the Central Asian region, out of 176 countries, as being highly corrupted. Kazakhstan obtained the 131st rank and the Kyrgyz Republic the 136th. Thus, governments in Central Asia, as with a significant number of other emerging countries are not perceived as trustworthy stakeholders to enhance economic and technological development (Bathula, Karia \& Abbott, 2011). At this point, the educational sphere seems to offer better conditions to reach the previously mentioned goals, as they form the bedrock of the next generation of leaders and new ideas. There is always a high degree of possibility for positive spillover from higher education.

Educational institutions, such as universities, have always been enclaves concerned with fostering dialogue between public and private spheres (Altbach, 2013). Moreover, in developing economies, their role is "extraordinarily important" (Altbach, 2013). Such institutions should be "committed to the creation and dissemination of knowledge, in a range of disciplines and fields, and featuring the appropriate laboratories, libraries, and other infrastructures that permit teaching and research at the highest possible level" (Altbach, 2013). Although a URCN or university-based incubator business model already exists in most developed economies, applying a similar or modified version of such a model in emerging countries can appear to be challenging and, in many cases, ground-breaking. This research explores the potential of a URCN in Central Asian context, and it's potentially far reaching impacts on R\&D and cross-border investments into the Eurasian Economic Union.

\section{Context and Literature Review}

There is still a dearth of understanding in terms of how these economies have been growing in the last 25 years. Despite acknowledging the real economic problems in $\mathrm{CA}$, the focus here is on the application of existing literature and studies from other 
countries to an analysis of CA university-industry collaboration to discover if established models can be useful in helping to understand their entrepreneurial characteristics. In a knowledge intensive society, the research university is a key institution for social and economic development. Research universities are institutions with a high priority on the discovery of new knowledge and the production of Ph.Ds. in wide range of disciplines.

According to responses from our interviewees, universities in Central Asia are gradually (in a minimal way) moving towards becoming Research Universities (RUs) or more entrepreneurial in their focus. This has been alongside a concerted push by governments in this direction in recent years.

This progress can be seen via the patent data from Kazakhstan (Table 2). Head to head, in all categories of patent type, public universities in Kazakhstan have performed well in the last five years. Authors complement this data set with a Kazakh patent concentration net (Figure 3). As expected, private sector entities are leading the way on research. What is interesting from the Table 2 is that various patent categories show a tremendous amount of invention compared to all other sectors except for private entities. For instance, inventions by individuals consist of $50.3 \%$ of all total inventions versus $23.6 \%$ only for other private entities. Conversely, other private entities, do dominate circa $71 \%$ of all industrial designs, across all sectors. Evidently, public institutes succeed in the area of selective achievements, approximately $63.5 \%$ of all achievements across all sectors.

Table 2. Patents in Kazakhstan from 2011 to 2015 years, by patent type

\begin{tabular}{|c|c|c|c|c|c|c|}
\hline Patent Type & $\begin{array}{c}\text { Public } \\
\text { Institute }^{1}\end{array}$ & $\begin{array}{c}\text { Private } \\
\text { Institute }^{2}\end{array}$ & $\begin{array}{l}\text { Other } \\
\text { Public }^{3}\end{array}$ & $\begin{array}{c}\text { Other } \\
\text { Private }^{4}\end{array}$ & Individual $^{5}$ & Total \\
\hline \multirow{2}{*}{ Inventions } & $10,6 \%$ & $9,5 \%$ & $6,0 \%$ & $23,6 \%$ & $50,3 \%$ & \\
\hline & 789 & 705 & 444 & 1750 & 3732 & 7420 \\
\hline \multirow{2}{*}{ Utility Models } & $7,3 \%$ & $3,1 \%$ & $0,6 \%$ & $41,2 \%$ & $47,8 \%$ & \\
\hline & 54 & 23 & 4 & 306 & 355 & 743 \\
\hline \multirow{2}{*}{ Industrial Designs } & $2,8 \%$ & $0,9 \%$ & $1,7 \%$ & $70,8 \%$ & $23,8 \%$ & \\
\hline & 33 & 11 & 20 & 826 & 277 & 1166 \\
\hline \multirow{2}{*}{ Selection Achievements } & $63,5 \%$ & $6,3 \%$ & $6,3 \%$ & $19,0 \%$ & $4,8 \%$ & \\
\hline & 269 & 27 & 27 & 81 & 20 & 423 \\
\hline \multirow{2}{*}{ Trademarks } & $1,5 \%$ & $1,0 \%$ & $3,5 \%$ & $92,5 \%$ & $1,5 \%$ & \\
\hline & 237 & 158 & 552 & 14589 & 237 & 15772 \\
\hline
\end{tabular}

Source: Kazakhstan Patent Database, aggregated from the official database web-site https://www.kazpatent.kz/

Note: ${ }^{1}$ Public Institute refers to Public Research University or Institute

${ }^{2}$ Private Institute refers to Private Research University or Institute

${ }^{3}$ Other Public refers to Public Organizations, Centers, and Laboratories

${ }^{4}$ Other Private refers to Private Companies, International Corporations, and Individual Ventures

${ }^{5}$ Individual refers to Number of patents hold by Individual owners not related to any legal entity

Kazakhstan patents concentration net shows clear direction towards trademark applications (approx. $62 \%$ of total patent applications). 


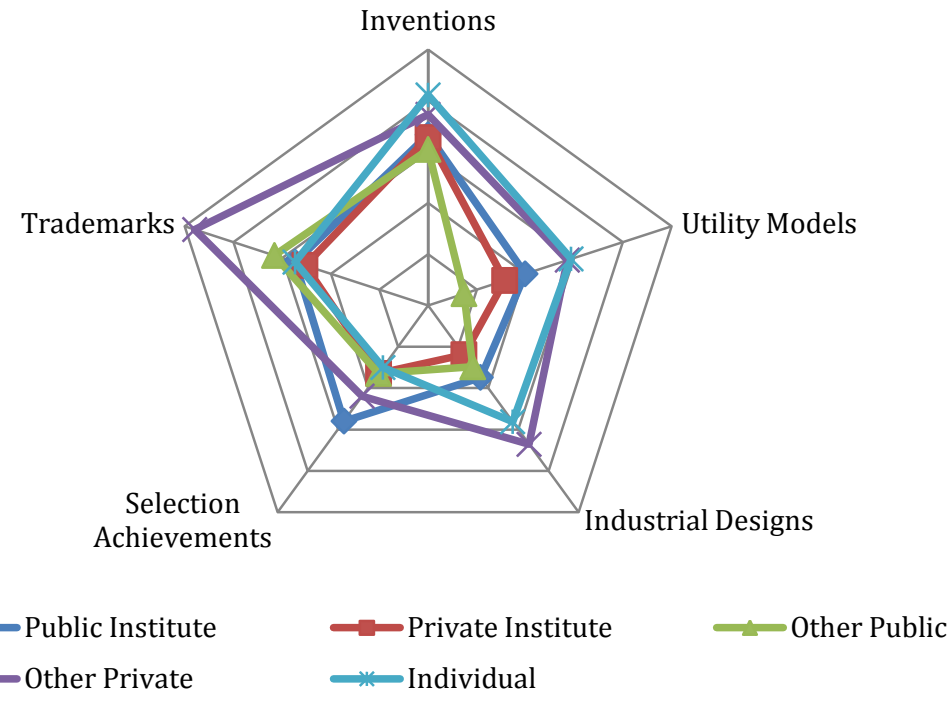

Figure 4: Kazakhstan Patents Concentration Net

Source: Kazakhstan Patent Database, compilation from the official database

Kazakhstan market accommodates foreign and local firms, which develop products and services not only for the local market, but also for the regional one, including Eurasian Economic Union countries and beyond. The inflow of FDI into the ecosystem largely contributed to the growth of scientific journal publications and patents applications (Table 2, Figure 9, and Figure 10). The intensity of patent applications is reflected in the areas of trademarks and industrial designs, while selection achievements and inventions represent relatively smaller portion of the total patent applications.

Uzbekistan patents concentration net (Figure 4) reflects similar trend of trademark applications although with larger magnitude (approx. $79 \%$ of total patent applications). Interestingly, $13 \%$ of all trademarks applications attribute to joint (foreign-domestic) firms and $4 \%$ to foreign firms, which are largely supported by Korean, Chinese, Japanese and other investment inflows. Uzbekistan revealed greater progress in terms of research and development compared to Kyrgyzstan and Tajikistan, which is reflected in the number of scientific and technical journal articles (Figure 9).

Tajikistan is of the poorest countries in Central Asian region. Due to the fact that resources are limited, Tajikistan policies and implications are less concentrated towards R\&D development. Thus, Tajikistan does not maintain the same intellectual property reporting practices, as opposed to Soviet Union period. 
Authors gathered and compiled available data, but realized that it is not enough to draw solid conclusions regarding Tajikistan R\&D policies. Prospective research should find a way to get access to data.

\section{Table 3. Patents in Uzbekistan from 2011 to 2015 years, by patent type}

\begin{tabular}{lcccccc}
\hline Patent Type & $\begin{array}{c}\text { Public } \\
\text { Institute }^{1}\end{array}$ & $\begin{array}{c}\text { Private } \\
\text { Institute }\end{array}$ & $\begin{array}{c}\text { Other } \\
\text { Public }^{3}\end{array}$ & $\begin{array}{c}\text { Other } \\
\text { Private }^{4}\end{array}$ & Individual $^{5}$ & Total \\
\cline { 2 - 7 } Inventions & $26,3 \%$ & $23,5 \%$ & $14,8 \%$ & $9,8 \%$ & $25,6 \%$ & \\
\hline \multirow{2}{*}{ Utility Models } & 140 & 125 & 79 & 52 & 136 & 532 \\
\cline { 2 - 7 } & $7,5 \%$ & $35,8 \%$ & $18,6 \%$ & $15,7 \%$ & $22,3 \%$ & \\
\hline \multirow{2}{*}{ Industrial Designs } & 34 & 162 & 84 & 71 & 101 & 452 \\
\cline { 2 - 7 } & $0,6 \%$ & $3,7 \%$ & $2,5 \%$ & $68,9 \%$ & $24,3 \%$ & \\
\hline \multirow{2}{*}{ Trademarks } & 3 & 18 & 12 & 334 & 118 & 485 \\
\hline & $0,1 \%$ & $0,4 \%$ & $0,5 \%$ & $89,9 \%$ & $9,1 \%$ & \\
\hline
\end{tabular}

Source: Agency on Intellectual Property of the Republic of Uzbekistan, aggregated from the official database web-site http://www.ima.uz

Note: ${ }^{1}$ Public Institute refers to Public Research University or Institute

${ }^{2}$ Private Institute refers to Private Research University or Institute

${ }^{3}$ Other Public refers to Public Organizations, Centers, and Laboratories

${ }^{4}$ Other Private refers to Private Companies, International Corporations, and Individual Ventures

${ }^{5}$ Individual refers to Number of patents hold by Individual owners not related to any legal entity

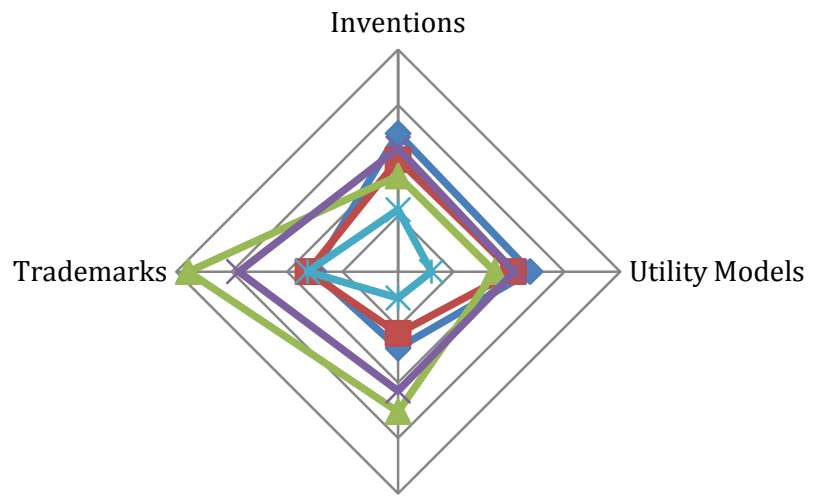

Industrial Designs

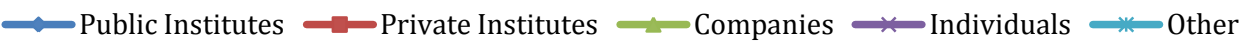

\section{Figure 5. Uzbekistan Patents Concentration Net}

Source: Agency on Intellectual Property of the Republic of Uzbekistan, compiled from the official database web-site, available online at: http://www.ima.uz 
Kyrgyzstan is one of the most democratic countries in Central Asia. After the collapse of the Soviet Union it was open to investment inflows, introduction of new practices into policy making bodies, knowledge sharing programs, development projects and more. Recent interview with experts of the Kyrgyz State Intellectual Property Service Agency highlighted that governmental bodies seek for best practices from developed economies, while adapting selected practices to Kyrgyz market realities (for more detailed information refer to findings section).

Table 4. Patents in Kyrgyzstan from 2011 to 2015 years, by patent type

\begin{tabular}{lcccccc}
\hline Patent Type / Year & 2011 & 2012 & 2013 & 2014 & 2015 & Total \\
\hline Inventions & 88 & 103 & 88 & 100 & 117 & 496 \\
\hline Utility Models & 10 & 17 & 9 & 10 & 17 & 63 \\
\hline Industrial Designs & 19 & 11 & 35 & 26 & 32 & 123 \\
\hline Trademarks & 606 & 672 & 684 & 600 & 650 & 3212 \\
\hline
\end{tabular}

Source: Compiled data from State Service of Intellectual Property and Innovation under the Government of the Kyrgyz Republic, 2015

The aggregated data from Kyrgyzstan, Kazakhstan and Uzbekistan from 2011 to 2015 years suggests similar patterns. All three countries are more inclined into trademarks rather than inventions or utility models, which are partially explained by lack of trust, insufficient or inexistent R\&D policies and investments. Some of these aspects are highlighted by interviewed participants of this study, who expressed their concern about insufficient capacity of innovative practices in the country.

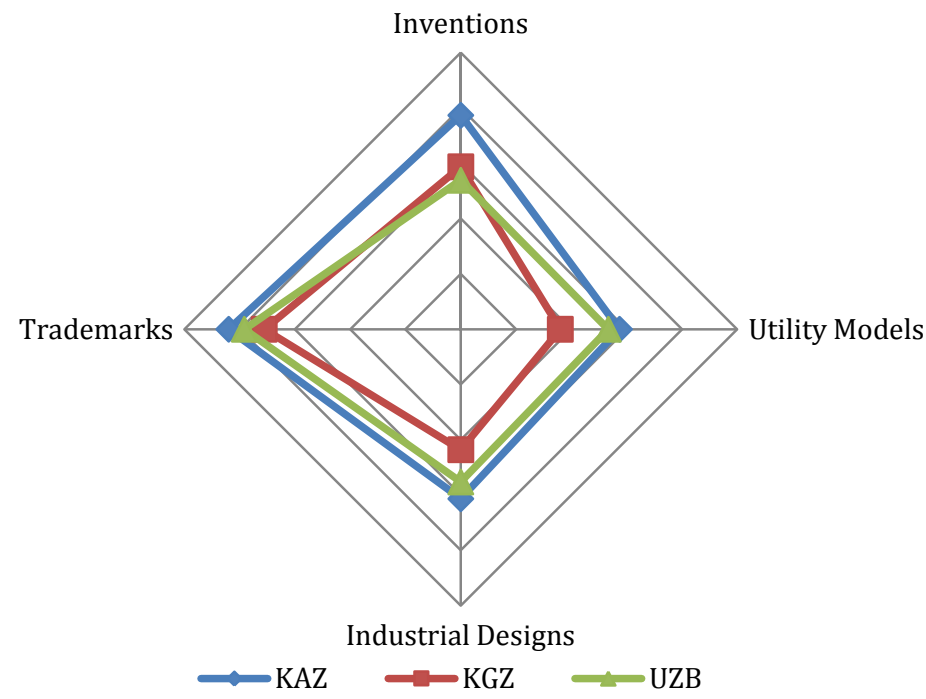

Figure 6. Kyrgyzstan, Kazakhstan and Uzbekistan Patents Concentration Net Source: Compiled data from Kazakhstan Patent Database, Agency on Intellectual Property of the Republic of Uzbekistan, State Service of Intellectual Property and Innovation under the Government of the Kyrgyz Republic 
Mohrman, Ma and Baker (2008, 5-6) have stated that, despite RUs key aim in imparting new knowledge, especially in science and technology-related areas, RUs continue to also educate undergraduates, train professionals for a wide range of positions, provide service to society, and engage in applied work and technology transfer. Such facilities were lacking in several of the interviewed universities. What is primarily needed is to create the necessary infrastructure, such as libraries, laboratories, technicians, and administrative support, to continuously coordinate scholarly work at the highest levels. In this regard, there is still a long road ahead towards building true cooperation between universities and companies in CA. Chesbrough (2003) found that this latter factor is a natural partnership in developed countries, where firms seek external sources of knowledge, despite having vast resources and their own R\&D laboratories.

One main fact that needs to be rehashed into CA government policies is that the increasing rate at which new products or innovative services appear on the market goes beyond the boundaries of firms, and cooperation with customers, suppliers, research institutes and even competitors. Acknowledging this is crucial. As such, cooperation is one way for CA countries to develop further, with universities acting as the main source of knowledge leading to innovation and, thus, agents of economic and social change. Etzkowitz (1983) was one of the first to identify such a role for the university, drawing attention to a new academic revolution resulting in the "capitalization of knowledge", the concept that evolved into the Triple Helix ${ }^{2}$. The helix results from the intersection of relatively independent institutional spheres and the formation of hybrid organizations such as technology transfer offices (TTOs) in universities and research institutes, alongside new funding agencies, such as venture capital companies and networks of angel investors (Etzkowitz 2003). Unfortunately, the established insular academic culture and prejudices tend to inhibit such collaboration in Central Asia.

Perkmann (2013), undertook an extensive review of the literature, and classified the relationships between universities and companies into two parts. It was found that collaborative research, consulting contracts and informal relationships for knowledge transfer were considered 'academic commitment'; while 'marketing' involved the creation of intellectual property and academic entrepreneurship. He notes that 'academic commitment' is the most practiced type, and differs from commercialization activities because they are strongly aligned to the traditional academic research, the goal of which is to raise funds for the researchers' working agenda.

In CA, particularly in Kazakhstan and Kyrgyzstan, there has been a gradual effort by universities to operate more entrepreneurially, developing informal networks or partnerships with private organizations and partner universities. Considering the

\footnotetext{
${ }^{2}$ This term refers to the key analysis of relationships between university-industry-government (UIG) or public-private partnership (PPP), explaining the components in a 'systems of innovation' framework and within a given institutional setting.
} 
limited role played by the respective States beyond their stated goals in policy documents to rapidly develop the higher education sector, the universities are left to fend themselves in terms of identifying and accessing research funding channels. While, Etzkowitz (1983, 2003), Etzkowitz and Leydesdorff (2000) and Etzkowitz Webster, Gebhardt, and Terra (2000), provided a thematic analysis of universities undergoing a 'second revolution' along the lines of existing economic and social development, this is far from the truth about the current situation in CA. This research, in a small way, hopes to illuminate the processes involved in chosen countries.

CA universities are still undergoing the first academic revolution, which relates to expanding their function from purely teaching alongside a limited number of focused research activities, to a broader R\&D and entrepreneurial role (Etzkowitz, 1994; Ropke, 1998; Laukkanen, 2000). However, with the increasing inflow of foreign academics and institutions invited by some of the CA universities, they have begun to integrate economic development as an additional function. These emerging entrepreneurial actions, however, have not yet been noted in the literature.

The literature generally supports the role of governments and their institutional arms in developing favorable environments to support public and private educational institutions. Such developments can be formalized through entrepreneurship at university levels, and the encouragement of closer collaboration between various economic units and universities. However, there is a dearth of evidence in the literature on how such activities are undertaken in the local contexts in CA. Key literature from outside of the region by Leclerc (1985), Shane (2004), Kirby and Mullen (1990), Kirby (1992), and Laukkanen (2000) have provided strong evidence of the role played by entrepreneurship curricula and training programs within the university toward advancing such collaboration. Peters and Etzkowitz (1990) research, though not CA based, indicates how these can be further extended by developing an all-inclusive system that supports values, norms, and attitudes necessary for a university culture and which are central to the development of entrepreneurial activities within the universities.

One cannot deny the importance of having dependable and transparent institutional structures to aid progress of universities from teaching to research, and further towards a more entrepreneurial character. Etzkowitz $(2003,109)$ provides an analysis of the transition of research universities towards top entrepreneurial universities. His study showed evidence of how the entrepreneurial dynamic of US universities originated in the late $19^{\text {th }}$ century, where they lacked formal research funding systems and placed premium on individual and collective initiatives to obtain revenues to support original investigation. Further, Petit and Soete (1999) found that entrepreneurial activities of such universities emerged 'bottom-up' in contrast to European counterparts, where it is a 'top-down' phenomenon, and that this is a factor in the significant 
innovation gap between the US and Europe. Understanding this relationship is the key for the development of an appropriate and effective model of URCN implementation in the CA region.

Etzkowitz and Leydesdorff (2000), presented three (Figure 6, Figure 7, \& Figure 8) configurations of the so-called 'Triple-Helix' model. Figure, provides a socialistic view of the arrangements, where state directs the activities of the industry and academia. Such models are purely of a 'top-down' approach of managing relations. These are mostly discouraging to innovation, which were present in the former Soviet Union and some Eastern European countries.

Figure 7 demonstrates the idea of a government system of non-interference, or which is very limited in nature, in the economic activities of the various institutional structures in the State. In other words, we see clear autonomous boundaries. Such arrangements are exemplified by Sweden and the US.

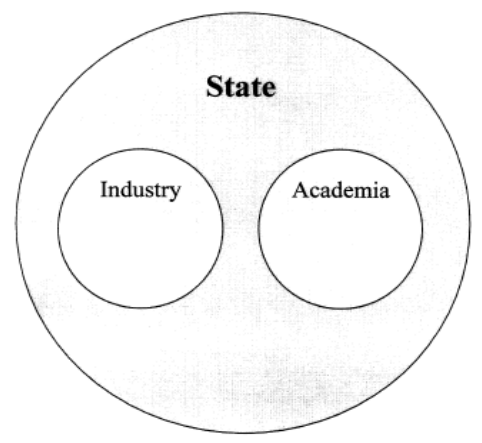

Figure 7. Static Model of University-Industry-Government Relations

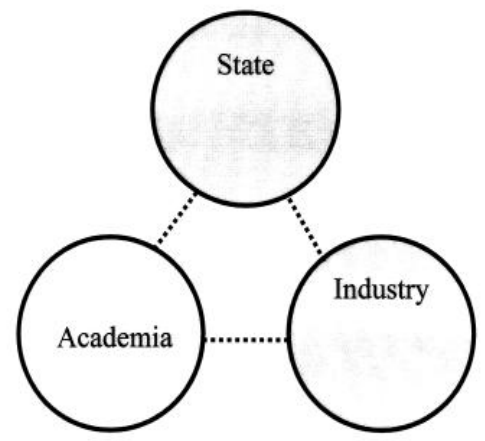

Figure 8. Laissez-Faire Model of University-Industry-Government Relations

Figure 8 provides an illustration of overlapping institutional structures, each taking on some roles of the others, with heterogeneous units emerging within the common boundaries. Such arrangements are what most developed economies (such as Singapore, Sweden, and Finland) are exploring at present. The main aim of such structure is to develop a common environment for innovation consisting of universities, spin-off firms, and tri-lateral initiatives to support knowledge-based economic development and strategic alliances among firms, government laboratories and academic research groups (Etzkowitz \& Leydesdorff 2000, 112). Incubators are common features of such arrangements. 


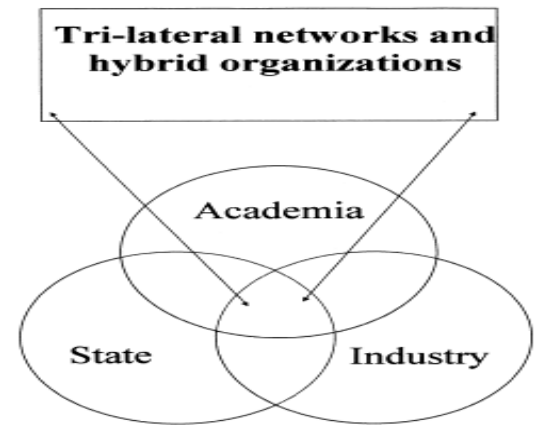

\section{Figure 9. The Triple Helix Model of University-Industry-Government Relations}

As we go through the various configurations of the 'Triple-Helix' model, one can clearly understand how the transformation of the institutional structures aids research and development and creates a framework for developing a knowledgebased economy. The speed of transformation of the university-industrygovernment relations is one which is dynamic in nature and requires a good amount of flexibility in innovative policy development. Formal relationships, such as collaborative agreements between science and industry, R\&D contracting, own licensing policies and intellectual property management and spin-off activities of science institutions are some of the innovative policy initiatives to be explored.

However, behind such initiatives and relationships lies a wide array of informal contacts, gatekeeping processes, personnel mobility and industry-science networks on a personal or organizational basis. These informal practices and intellectual capital flows are ways of exchanging knowledge between enterprises and public research - creating spill-overs - and are more difficult to quantify, but nevertheless extremely important and often are the catalyst for formalizing further formal contacts. This idea is supported by Grossman, Reid and Morgan (2001), who have focused, not on the broad spectrum of science-industry links and intellectual property as has most of the existing literature, but analyzed the more dynamic role played by informal networks or social pathways.

The idea that these informal initiatives and relationships often form the basis for later formal networks is also supported by Scandinavian and Asian cases of R\&D development. Given this, an understanding of the initiatives and relationships currently in place in the CA region is crucial to the identification and development of an appropriate and effective URCN model. Our research, conducted through interviews with academics working in established private and public university institutions in Kazakhstan and Kyrgyzstan is aimed to fulfill the knowledge gap.

Taking into account the characteristics and innovative policy approaches of the Scandinavian and Asian economies, Table 5 provides a basic typology of university- 
industry links that could be a starting base for analyzing the situation and informal structures extant in the cases of Kyrgyzstan and Kazakhstan.

\section{Table 5. Basic Typology of University-Industry Links}

\begin{tabular}{ll}
\hline $\begin{array}{l}\text { Research } \\
\text { partnerships }\end{array}$ & Inter-organizational arrangements for pursuing collaborative R\&D \\
\hline Research activities & $\begin{array}{l}\text { Activities commissioned by industrial clients including contract } \\
\text { research and consulting }\end{array}$ \\
\hline $\begin{array}{l}\text { Academic } \\
\text { entrepreneurship }\end{array}$ & $\begin{array}{l}\text { Development and commercial exploitation of technologies pursued } \\
\text { by academic inventions through a company they (partly) own }\end{array}$ \\
\hline $\begin{array}{l}\text { Human resource } \\
\text { transfer }\end{array}$ & $\begin{array}{l}\text { Multi-context learning mechanisms such as training of industry } \\
\text { employees, postgraduate training in industry, graduate trainees and } \\
\text { secondments to industry, adjunct faculty }\end{array}$ \\
\hline Informal interaction & Formation of social relationships and networks at conferences, etc. \\
\hline $\begin{array}{l}\text { Commercialization of } \\
\text { property rights }\end{array}$ & $\begin{array}{l}\text { Transfer of university-generated IP (such as patents) to firms, e.g. } \\
\text { via licensing }\end{array}$ \\
\hline $\begin{array}{l}\text { Scientific } \\
\text { publications }\end{array}$ & Use of codified scientific knowledge within industry \\
\hline Source: Perkmann. M., \& Walsh. K, (2007: 252), International Journal of Management Review.
\end{tabular}

\section{Research Findings}

In Table 5 identified qualities, characteristics and links can be found in URCNs. Based on our research interviews (discussed below), it is clear that, while some characteristics are present, they require further development. According to our findings, scientific publications, commercialization of property rights (minimal in CIS countries) and informal interaction form the base of the types of research and development activities (low intensity) which are conducted in Kyrgyz and Kazakh universities. Additionally, similar patterns, excluding small deviations are observed in Uzbekistan and Tajikistan (Figure 10 \& Figure 11).

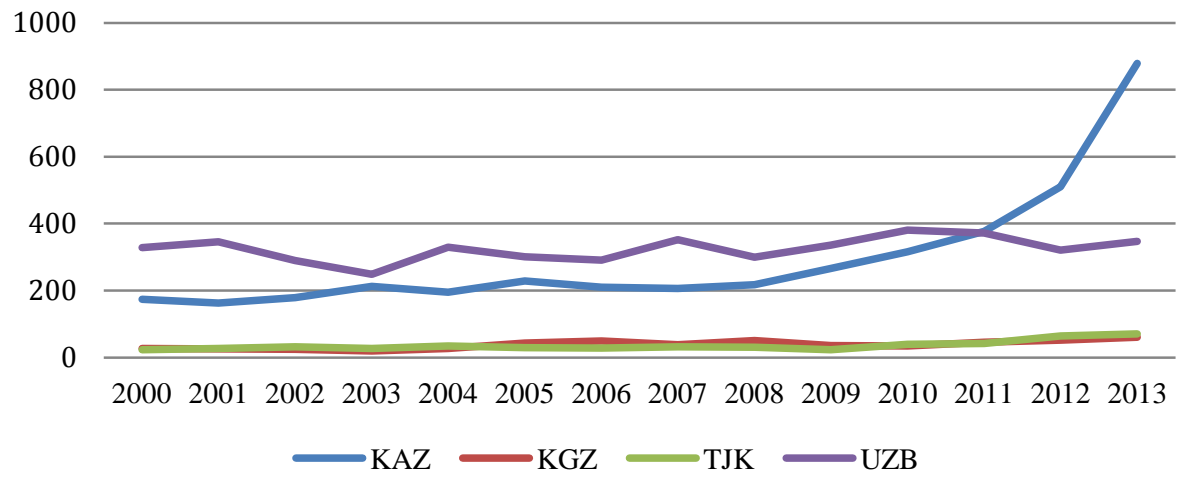

Figure 10. Scientific and Technical Journal Articles

Source: Compilation from World Bank Data, available online at: https://data.worldbank.org/indicator 
Furthermore, the interviews indicate that academic entrepreneurship and human resource transfer situations are recently being explored by Kyrgyz and Kazakh universities. However, such activities, considered to be of middle intensity, are still in a state of confusion due to lack of support from top university administration or from the state. It will take a strong push and encouragement from various institutional structures to make progress along this route. Research partnerships and research services require a strong acceptance, trust and support from various parties and stakeholders to move towards such high-intensity arrangements. This latter form is completely non-existent and is supported by the research interviews.

In addition, the progression from teaching, to research and entrepreneurial university roles in Kyrgyzstan and Kazakhstan is still at the infancy stages. Through the research interviews, it became evident that the lack of support for such progression is largely attributable to the lack of financing available to universities, which often left them with an insufficient capacity to join industry in innovationrelated projects, largely supported by the research and development expenditure as a percent of GDP (Figure 1). Building effective university-industry linkages in this context takes time and sustained effort. This is largely due to the fact that universities in developing or emerging markets have little or no experience in industry collaboration and limited managerial capacity in research, in addition to the issues of mistrust, corruption and transparency. As such, the argument boils down to the fact that collaborations between universities or between university and industry are constrained by historically rooted cultural and institutional barriers.

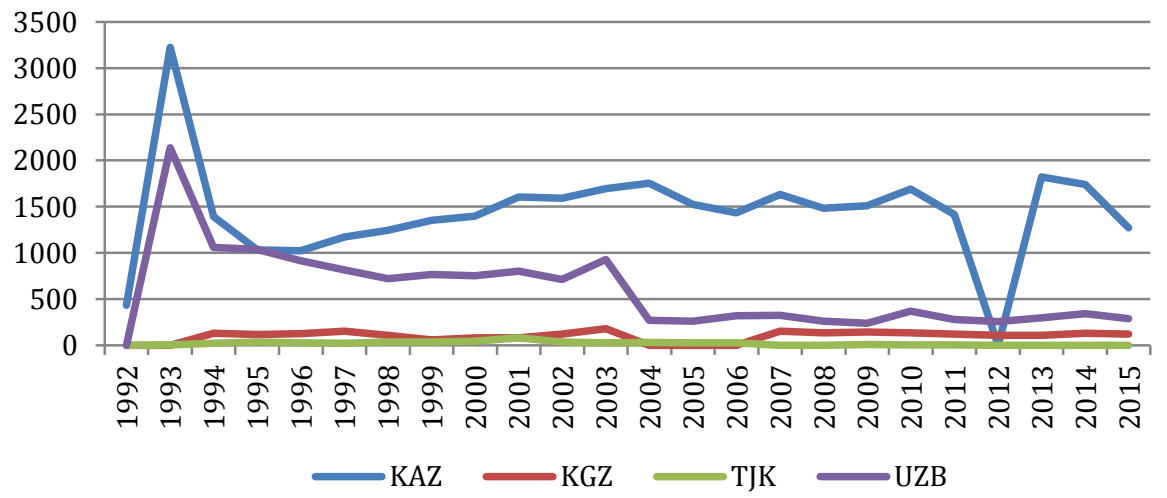

Figure 11. Patent applications, Residents; from 1992 to 2015

Source: Compilation from World Bank Data, available online at: https://data.worldbank.org/indicator

Several patterns emerged during the research interviews ${ }^{3}$. Our results show that the process of collaboration and knowledge sharing is very complex and

\footnotetext{
${ }^{3}$ Data was collected by structured interviews in public and private universities in Kyrgyzstan and Kazakhstan.
} 
challenging. It involves a myriad of settings that influence the relationship between universities; however, initial analyses of the findings show that there is a common pattern across both public and private universities in Kyrgyzstan and Kazakhstan.

The main findings are:

1. The most important point is that all participants are fundamentally interested in creating a cooperative network between universities. The finding coincides with our initial conjecture of the desirability of a URCN. The universities emphasized the importance of legal frameworks in structuring such a network. The interviewees stated that there was no support from the government oriented at enhancing collaboration. In the Kazakh case, the government tried to generate a framework; however, it was very weak and requires additional revisions for successful implementation. As for Kyrgyzstan, there are no existing laws that would enhance any kind of cooperation between universities. Moreover, the government just recently started introducing notions such as 'research based education' in the legal context.

2. International programs such as Erasmus+ enhance cooperation, not only on international level, but also on regional and national levels. Approximately $80 \%$ of the universities stated that they developed their cooperation on the local level by participating in mobility programs mainly financed by the European Union. The pattern is very similar in terms of research collaboration as well. Mobility programs offer the possibility for local professors to receive training abroad and then, upon their return, to host training for other professors from remote areas. In this way, there is a dual benefit.

3. At this stage, the individuals inside the universities are the most important links on research collaboration levels. Collaboration is mainly executed on individual levels involving personal connections. Given the reality that both country examples were part of the former Soviet Union, the expectations of centrally planned actions still persist. This is valid especially for public institutions. Our qualitative findings show that these institutions are not willing to transfer knowledge either to other universities or to industry without any solid legal framework.

4. Another major conclusion is that the majority of universities are teachingoriented. This style was also inherited from the former Soviet Union education system. There are very few universities that perform solution-driven research on a systematic basis. There are even fewer universities that create patents and trademarks. We also observed that quantification and monitoring systems of intellectual outcomes are very primitive and outdated. There is only one example of a university that has the capacity to perform solution driven research and monitor its implementation accordingly.

5. University-industry collaboration is very weak. Both in Kazakhstan and Kyrgyzstan, the private sector does not trust universities' expertise. The private sector considers it to be much more convenient to contract a private company 
rather than a university to undertake research and development. As a result, private and university-led business and scientific incubators are not as strong as they should be.

6. For one private university in Kazakhstan, the scientific incubators are at an incipient phase, and do not appear to deliver strong results, even though the funding and the infrastructure is quite developed.

7. Kyrgyz State Intellectual Property Service Agency highlighted the ongoing progress in terms of Techno-Parks on the basis of Universities, which eventually will accommodate TTOs that are not in place at the moment. The State Agency actively collaborates with universities, companies and other public agencies, although it mentions rare cases of joint collaboration between university and industry. It is important to highlight that the capacity of innovations department is not enough to progress towards rapid R\&D development. Limited funding, lack of skilled work force and inexistence of supportive policies postpone technological and innovative transformation of R\&D development in Kyrgyzstan.

8. Kyrgyz State Intellectual Property Service Agency mentioned that European model of R\&D development fits Kyrgyz milieu the most. It actively collaborates with Estonian partners, who are willing to provide required support in terms of training and policy advising.

Keeping in line with the information gathered from the structured interviews, this paper found the following taxonomy, proposed by Guimon, J. (2013), to fit the proposition of URCN creation.

\section{Table 6. Priorities for University-Industry partnerships at different stages} of Economic Development

\begin{tabular}{|c|c|c|}
\hline & Most developed countries & Least developed countries \\
\hline $\begin{array}{l}\text { Teaching } \\
\text { University }\end{array}$ & $\begin{array}{l}\text { - Private participation in graduate } \\
\text { programs } \\
\text { - Joint supervision of PhD students }\end{array}$ & $\begin{array}{l}\text { - Curricula development to improve } \\
\text { undergraduate and graduate } \\
\text { studies } \\
\text { - Student internships }\end{array}$ \\
\hline $\begin{array}{l}\text { Research } \\
\text { University }\end{array}$ & $\begin{array}{l}\text { Research consortia and long-term } \\
\text { research partnerships to conduct } \\
\text { frontier research }\end{array}$ & $\begin{array}{l}\text { - Building absorptive capacity to } \\
\text { adopt and diffuse already existing } \\
\text { technologies } \\
\text { - Focus on appropriate technologies } \\
\text { to respond to local needs }\end{array}$ \\
\hline $\begin{array}{l}\text { Entrepreneurial } \\
\text { University }\end{array}$ & $\begin{array}{l}\text { - Spin-off companies, patent licensin } \\
\text { - Entrepreneurship education }\end{array}$ & $\begin{array}{l}\text { - Business incubation services } \\
\text { - Entrepreneurship education }\end{array}$ \\
\hline
\end{tabular}

In case of interviewed universities (public and private), all participants clearly noted that their activities are in conjunction with the teaching stage and located under the least developed countries category. Despite the dramatic increase in economic activity in the last 10 years, there has been very limited progress towards the creation of a research university category. While there are glimpses of positive 
vibes voiced by some of the interviewees in terms of progress towards an incubator-led and entrepreneurial-led environment, none have a concrete pathway or innovative policy prescription to move forward. Most are awaiting external impetus in the form of FDI or some form of government policy and financial incentive to undertake such activities. In fact, some universities in Kyrgyzstan collaborate informally with external agents to simply cut-off the government's role and seek a quick route to commercialization and profit-making, claiming that it is a tedious process to deal with the government in patent licensing.

\section{Policy Prescriptions and Future Research}

The paper began by proposing the development of a network-led research consortium within the CIS countries to create a positive-spillover effect towards $R \& D$ development. What was found throughout the paper is that the role of universities in the two countries, Kyrgyzstan and Kazakhstan, match the empirical realities in low and middle income nations. The qualitative study, along with theories found elsewhere, highlights the state of play in the case of Kyrgyzstan and Kazakhstan. The systemic conditions and capabilities of universities and peculiarities of government and private sector interaction require clearer policies for an overhaul of the higher education system that is long overdue.

The use of compare and contrast strategy in this paper, the conceptual-refinement in relation to university-firm relations provided insights into informal channels of interaction. In addition, for future research extension of this topic, must undertake a close analysis of the Scandinavian and Asian regions to emphasize the perspective of the role of government and university administration in latching on to new developments by devoting larger amounts of resources to overhaul the higher education sector and to formalize arrangements with external stakeholders to promote a culture of research and entrepreneurial behavior.

Successful university-led consortia or university-industry collaboration needs to support the missions and motivations of each participant. The typical motivations of universities to collaborate with industry will include the improvement of teaching, access to funding, reputation enhancement and access to empirical data from industry. On the other hand, firms are motivated to collaborate to gain access to complementary technological knowledge, tap skilled workers, and provide training to existing or future employees, gain access to university facilities and equipment, and gain access to public funding and incentives. There is a possibility that firms also seek to reduce risks by sharing costs of R\&D, and to influence the overall teaching and research agenda of universities.

Despite the above positives towards URCN development in CA, many barriers exist and were evident in from the two-country study. Firstly, research aims of universities did not align with the research interests of firms. A large concern from the interviewees was that, firms are mostly interested in getting the product to market first and in profit maximization. This discourages universities from 
undertaking basic research which then naturally does not incentivize research and development. Studies have shown that collaboration is costly and returns are only seen in the medium to long term horizon.

Secondly, even if there is any form of collaboration inked, firms push to obtain new patents or new products, and do not want to disclose information externally. However, university researchers are naturally interested in publishing their results. Thirdly, an important issue of key concern in research is intellectual property rights (IP) and deriving profits. As it was noted in the interviews, the IP and legal frameworks at present are either weak or non-existent in many cases. There is also no institutional support from the government or universities. Last, but not least, there is no expertise in the respective universities in terms of negotiating collaboration, especially when information is lacking, nor in finding the correct partners, determining who is trustworthy, and knowing how transaction costs are to be managed.

While it is easy to acknowledge the concerns of the interviewees, it must be noted that, in both developed and developing countries, universities have looked to governments to fund research efforts (such as the research and innovation policies developed by the Asian economies). Pau (2003) found that government direct investment in research has been augmented with the new public policies that facilitate partnerships between research universities and corporate entities. This coincides with the 'Triple Helix' model discussed earlier in the report. However, the main concern in the cases of Kyrgyzstan and Kazakhstan, particularly Kyrgyzstan, is that there is large black hole in policy initiatives in terms of capacity and skilled sets in areas of research, which requires concerted or good deal of effort from the government and its state institutions to urgently seek help from external stakeholders or foreign governments who have successfully developed policies in their respective countries. One example to explore would be that of countries like Singapore, which have successfully developed, from the scratch, their research and development policies to navigate growth towards a highly-advanced economy. The question to be posed here would be how it was possible for a nation with no hinterland, no resources and, initially, a small unskilled labor force, to develop rapidly to join the ranks of advanced economies. Singapore could be used as a hybrid model for future research extensions in the area of URCN.

Careful and critical analysis of best practices and policies from Singapore or other advanced Asian economies could offer some possibilities. For instance, it could be highlighted that the state could play a direct role in providing initial funds to universities and R\&D projects, as well as through a regulatory role, which influences the rule-sets of public universities and shapes the intellectual property rights regime. Another area in which the state could offer support is through the provision of the necessary infrastructure and intermediate organizations such as technology transfer offices (TTOs), science parks, and business incubators. Other soft measures (as practiced in Singapore) could also be implemented, such as the 
stimulation of collaboration by providing specific support services to firms/universities in the search for partners and conducting outreach activities to promote networking and raise awareness of the importance of collaboration.

Yet another solution for stimulating university-industry collaboration is to formulate creative R\&D research grants, matching grants, and tax-incentives with the help of professional consortium of firms and universities for project eligibility. This was undertaken in the case of Singapore, where a policy instrument to promote collaboration was successfully applied. While larger MNCs setting up bases provided a more complex and varied arrangement for undertaking research locally, local small and medium enterprises (SMEs) are provided lines of credit to purchase services from universities and public research centers, with a view to introducing innovative practices in firms' business operations.

Since sincere efforts must come from the respective governments, especially in these parts of the world, the state can explore policy measures that determine how funding is provided for public universities and can include indicators like numbers of students, PhD graduates, scientific publications, and patents. Other measurable initiatives could take the form of the number of consulting or R\&D contracts that universities undertake with firms, income from patent licensing, number of spinoffs, and number of start-ups by university faculty or graduates. Yusuf $(2007,10)$ found that countries like India and Singapore offer universities supplementary earmarked funding for research, conditioned on the university achieving a certain level of contracts with industry, spinoffs, or start-ups.

In relation to the above point, governments can further establish policies that can reward university professors and researchers by encouraging or offering incentives to search for opportunities to collaborate with industry. This is an important measure and policy initiative as teaching experience and publications continue to be the dominant criteria for salary scales, with cooperation with industry never rewarded in most universities. A 2012 Australian Advisory Council on Intellectual Property (AACIP, 2012, 13-14) supports a policy initiative instituting key performance measures for public universities and research centers, developing mechanisms to increase the motivation of universities and their researchers to collaborate with industry.

As indicated several times by interviewees, IP regime is not strong among the universities and, further, there are no offices dedicated to technology transfer service activities. According to studies by Zuniga $(2011,5)$ it was found that since the 2000s, many low- and middle-income countries - in particular China, Brazil, Mexico, South Africa, Malaysia and Philippines - have followed the path of stimulating patent activity in universities and enabling commercialization of the research products using the US and OECD experiences. Some polices that were adopted consist of voluntary guidelines for IP management and codes of conduct in collaborative projects. 
In recent years, it has become a fashion in many global universities to undertake the creation of TTOs where assistance is provided to researchers in patenting their findings and obtaining license fees and royalties (Correa \& Zuniga 2013). TTOs are helpful in many ways to researchers and their services range from improving the technology transfer cycle, offering support in the patent application process, licensing agreements, search for partners and funding sources, and training and support in the creation of university-based spin-offs.

Again, IP reform and commercialization efforts cannot compensate for a country's weak national innovation system. This factor must be considered seriously before Kyrgyzstan and Kazakhstan can make any in-roads towards research and technology development. Hence for commercially viable or spin-off companies to evolve, or patent licensing opportunities to develop in a big way, there needs to be a continuous and sustainable push in R\&D to ensure appropriate technological capabilities and linkages exist. Once appropriate technological capabilities and linkages begin to exist, and skilled capacity increases, efforts could be focused towards developing science parks within the vicinities of universities. This could possibly spur university research spin-offs and start-ups with university collaborations. These latter actions could be appropriately garnered via public venture capital and grants to entrepreneurs. In recent years, huge expansions in science parks in many parts of the world have been highlighted in the literature. While not all low and middle-income countries can successfully implement or develop such tech parks due to the lack of necessary endowments that should not put off developing economies like Kyrgyzstan and Kazakhstan as these could offer newer opportunities. What is important is to set realistic achievements and assessments expected within an allowable regulatory arrangement, as opposed to simply rushing to transplant such models developed elsewhere.

Having noted key policy prescriptions, the most important of all policies is the ability to create a pool of educated and skilled graduates. The success stories of Singapore and other East Asian economies would clearly note that the impetus towards a higher technology growth path is to have a solid foundation of good education policy. Continuous learning, skill upgrading and the push towards graduate education would mean possibilities of attracting FDI and opportunities from the international market. For many firms, domestically and internationally, the most important link to a university is through recruitment of skilled graduates. In the case of Kyrgyzstan and Kazakhstan, and along with many other lower income countries, the lack of skilled workers is a major bottleneck hindering the competitiveness and innovative capacity of firms. The case of Singapore would be a good example to highlight. Government was consistently involved with the industry by fostering a stronger collaboration of universities with industry. Increased tax incentives, easy access to a skilled and English-speaking labor pool, access to capital, and continuous consultative process with business managers of local SMEs and MNCs is considered in curriculum development so that university programs better respond to industry needs. 
Other areas where policies could be well supported is through the establishment and support of student internship programs for undergraduates, as well as through seeking the participation of firms in graduate programs, and even the joint supervision of PhD students, who may undertake part of their research within firms. For example, in Chile, within the context of the Science for the Knowledge Economy Project financed by the World Bank, the government offered scholarships for PhD students and young researchers to conduct their research in firms (Guimon, 2013). This would allow knowledge diffusion from university-led R\&D institutes and enhances career paths of young researchers. There would also be a possibility to attract long-term employment opportunities in firms, leading to a sustainable increase in private sector's R\&D capacity.

Finally, the globalization of innovation brings both opportunities and challenges for developing countries. In the last three decades, MNCs have substantially expanded their global innovation networks, and their aim to collaborate with universities located abroad has been identified as one of the main drivers of the internationalization of their R\&D centers. Countries like Singapore and Taiwan have been quick to identify these opportunities and have developed tailored policies to stimulate collaboration between multinational subsidiaries and local universities as a mechanism to attract their R\&D activity and to enhance local learning and technology transfer. There have been a growing proportion of these offshore R\&D centers located in developing countries. However, such policy opportunities will not be beneficial now for countries like Kyrgyzstan and Kazakhstan, simply because appropriate conditions, including human capital, universities and public research institutes, clusters of innovative local firms, and innovation-friendly regulatory regimes, have yet to be properly developed. As such, this could be left to be analyzed in future research.

\section{Conclusion}

This research undertook an ambitious effort to study the feasibility of a universityled research consortium network in the contexts of Kyrgyzstan and Kazakhstan. Based on the analysis of what has been done elsewhere in the world and the undertaking of structured informant interviews, both in public and private universities from the above-mentioned countries, the level of progress toward and potential for the development of URCN in CA was analyzed. The local results show that there are minimal or even non-existent research and development policies within these universities. Most of these were either informally undertaken and/or undertaken through social networks. There also appears to be limited interest from top management in investing in or outlining strategies for R\&D collaboration, despite the growing number of scientific publications from some of the universities that were investigated. Most of the universities are still lacking in basic research departments, and are focused mostly on teaching. A further regional challenge is the lack of the government support in selecting policy instruments that best serve national needs. Limited budgets, inability to undertake any form of collaboration in 
education and research between universities and/or with industry, and difficulty in attaining grants or developing science parks, are some major themes found in the interviews.

While exploring the feasibility of URCN development within Kyrgyzstan and Kazakhstan, some research networks were observed. In other words, existing models of R\&D and university-led collaborations had to be carefully assessed and studied within their country contexts. The paper found that simply adopting or adapting existing models found elsewhere would not work in the current contexts. The study of the various economic regions supported the argument that URCNs are not based on a static model, but rather are developed out of current social, historical and cultural contexts and need to be adapted to the environment in which they are being developed. To become formally established, policy variables, cultural conditions and, most importantly, the existing initial conditions must be considered. This will go a long way toward the development of national innovation systems in CA countries.

Therefore, policy directions for the CA countries can be developed using best practices found in and adapted from many other developed and developing economies. The key to forward progress for the universities located on Kyrgyzstan and Kazakhstan is to invest a good deal of time in understanding where they are lacking, and toward creating strategies with the government to aid them towards their missions and objectives. If the economic growth of these studied countries is to progress toward technology advancement or a knowledge based framework, appropriate government involvement and sustainable policies should be investigated. This does not, however, represent the final point of research into this subject. More empirical evidence on the success of specific policy programs to support URCNs in these countries or other developing countries are needed, and would be a starting point for future research.

\section{Acknowledgements}

This research was conducted at the American University of Central Asia (AUCA) with the support of funding from the USAID "Building the Future" Grant. The purpose of this grant is to develop the scope of scholarship and research conducted at AUCA in accordance with USAID's mandate to enable resilient, democratic societies to realize their full potential. Building the Future projects were thus chosen for funding on the basis of their ability to advance scholarship in the fields of sustainable development, energy, security, business, investment, democracy, and/or the rule of law in order to aid in the broader development of Kyrgyzstan and the Central Asian region.

Opinions and interpretations expressed in this report are those of the authors alone and do not represent the point of view of USAID or the American University of Central Asia.

We would like to thank our colleagues from Universities in Kyrgyzstan and Kazakhstan who provided insights and expertise that greatly assisted this research. We would like to thank 
our colleagues from the Kyrgyz Patent Agency of the Kyrgyz Republic for providing comments, suggestions and data for this research.

The earlier version of this paper was presented at AUCA Research Seminar in September 2017.

\section{References}

AACIP (2012). Collaborations between the Public and Private Sectors: The Role of Intellectual Property-Final Report. Canberra: Australian Advisory Council on Intellectual Property, Government of Australia.

Altbach, P. G. (2013). Advancing the national and global knowledge economy: the role of research universities in developing countries. Studies in Higher Education, 38(3), 316-330. https://doi.org/10.1080/03075079.2013.773222

Bathula, H., Karia, M., \& Abbott, M. (2011). The role of university-based incubators in emerging economies (No. 22). Working paper.

Becker, J., \& Weissenbacher, R. (2007). Dollarisation, Euroisation and Financial Instability. In Dollarisation in Latin America and Euroisation in Eastern Europe: Parallels and Differences, by J. Becker, 223-278. Marburg, Germany: Megropolis.

Chesbrough, H. (2003). Open innovation: The new imperative for creating and profiting from technology. MA: Harvard Business School Publishing.

CIA World Fact Book (2013). The World FactBook. Retrieved June 2, 2017 from https://www.cia.gov/library/publications/download/download-2013/

Correa, P., \& Zuniga, P. (2013). Public Policies to Foster Knowledge Transfer from Public Research Organizations. The World Bank Report № 90534.

Etzkowitz, H. (1994). Academic-Industry Relations: A sociological paradigm for economic development. In Evolutionary Economics and Chaos Theory: New Directions in Technology Studies, by L Leydesdorff and P van de Besselaar, London: Pinter.

Etzkowitz, H. (1983). Entrepreneurial scientists and entrepreneurial universities in American academic science. Minerva, 21(2-3), 198-233.

Etzkowitz, H. (2003). Research groups as "quasi-firms": the invention of the entrepreneurial university. Research Policy, (32), 109-121. https://doi.org/10.1016/S0048-7333(02)00009-4

Etzkowitz, H., Webster, A., Gebhardt, C., \& Terra, B. R. C. (2000). The future of the university and the university of the future: evolution of ivory tower to entrepreneurial paradigm. Research policy, 29(2), 313-330. https://doi.org/10.1016/S0048-7333(99)00069-4

Etzkowitz, H., \& Leydesdorff, L. (2000). The dynamics of innovation: from National Systems and "Mode 2" to a Triple Helix of university-industry-government relations. Research Policy, 29(2), 109-123. https://doi.org/10.1016/S0048-7333(99)00055-4

Grossman, J. H., Reid, P. P., \& Morgan, R. P. (2001). Contributions of academic research to industrial performance in five industry sectors. The Journal of Technology Transfer, 26(1-2), 143-152. https://doi.org/10.1023/A:1007848631448

Guimón, J. (2013). Promoting university-industry collaboration in developing countries. World Bank, The Innovation Policy Platform: Policy Brief.

Kirby, D., A. (1992). Developing graduate entrepreneurs: the UK Graduate Enterprise Programme. Entrepreneurship, Innovation and Change, 1(2), 165-177. 
Research and Development Transformation in Central Asia: University-led Research ...

Kirby, D., A., \& Mullen, D. (1990). Developing enterprising undergraduates. Journal of European Industrial Training, 14(2), 27-32.

Laukkanen, M. (2000). Exploring alternative approaches in high-level entrepreneurship education: creating micro-mechanism for endogenous regional growth. Entrepreneurship \& Regional Development, 12, 25-47. https://doi.org/10.1080/089856200283072

Leclerc, W. (1985). Universities and Entrepreneurs. Journal of Small Business and Entrepreneurship, 3(2) 41-47. https://doi.org/10.1080/08276331.1985.10600229

MacLeod, D. (2002). Universities 'should be assests to local economy'. Retrieved June 10, 2017 from https://www.theguardian.com/education/2002/sep/17/highereducation.uk2.

Mohrman, K., Ma, W., \& Baker, D. (2008). The Research University in Transition: The Emerging Global Model. Higher Education Policy, 21(1), 5-27. https://doi.org/10.1057/palgrave.hep.8300175

Pau, B. (2003). From knowledge to innovation: Remodeling creative and knowledge diffusion processes. In Universities and Globalization: Private Linkages, Public Trust, by G Breton and M Lambert. Paris: UNESCO.

Perkmann, M., T. (2013). Academic Engagement and Commercialization: A review of the Literature on University-Industry Relations. Research Policy, 42(2), 423-442. https://doi.org/10.1016/j.respol.2012.09.007

Perkmann, M., \& Walsh, K. (2008). Engaging the scholar: Three types of academic consulting and their impact on universities and industry. Research Policy, 37(10), 1884-1891

Peters, L., S., \& Etzkowitz, H. (1990). University-industry connections and academic values. Technology in Society, 12, 427-440. https://doi.org/10.1016/0160-791X(90)90013-3

Ropke, J. (1998). The entrepreneurial university, innovation, academic knowledge creation and regional development in a globalized economy. Working paper, Marburg, Germany: Philipps-Universitat.

Shane, S. (2004). Encouraging university entrepreneurship? The effect of the Bayh-Dole on university patenting in the United States. Journal of Business Venturing, 19, 127-151. https://doi.org/10.1016/S0883-9026(02)00114-3

Petiti, P., \& Soete, L. (1999).Globalization in search of future. International Social Science Journal, 51(2), 165-181.

Yusuf, S. (2007). University-Industry Links: Policy Dimensions. In How Universities Promote Economic Growth, by S Yusuf and K Nabeshima, 1-26. Washington DC.

Zuniga, P. (2011). The State of Patenting at Research Institutions in Developing Countries: Policy Approaches and Practices. Geneva: WIPO Economic Research Working Papers 4.

World Bank Data (2017), retrieved June 27, 2017 from https://data.worldbank.org/indicator. 